\title{
A massive surgeonfish aggregation creates a unique opportunity for reef sharks
}
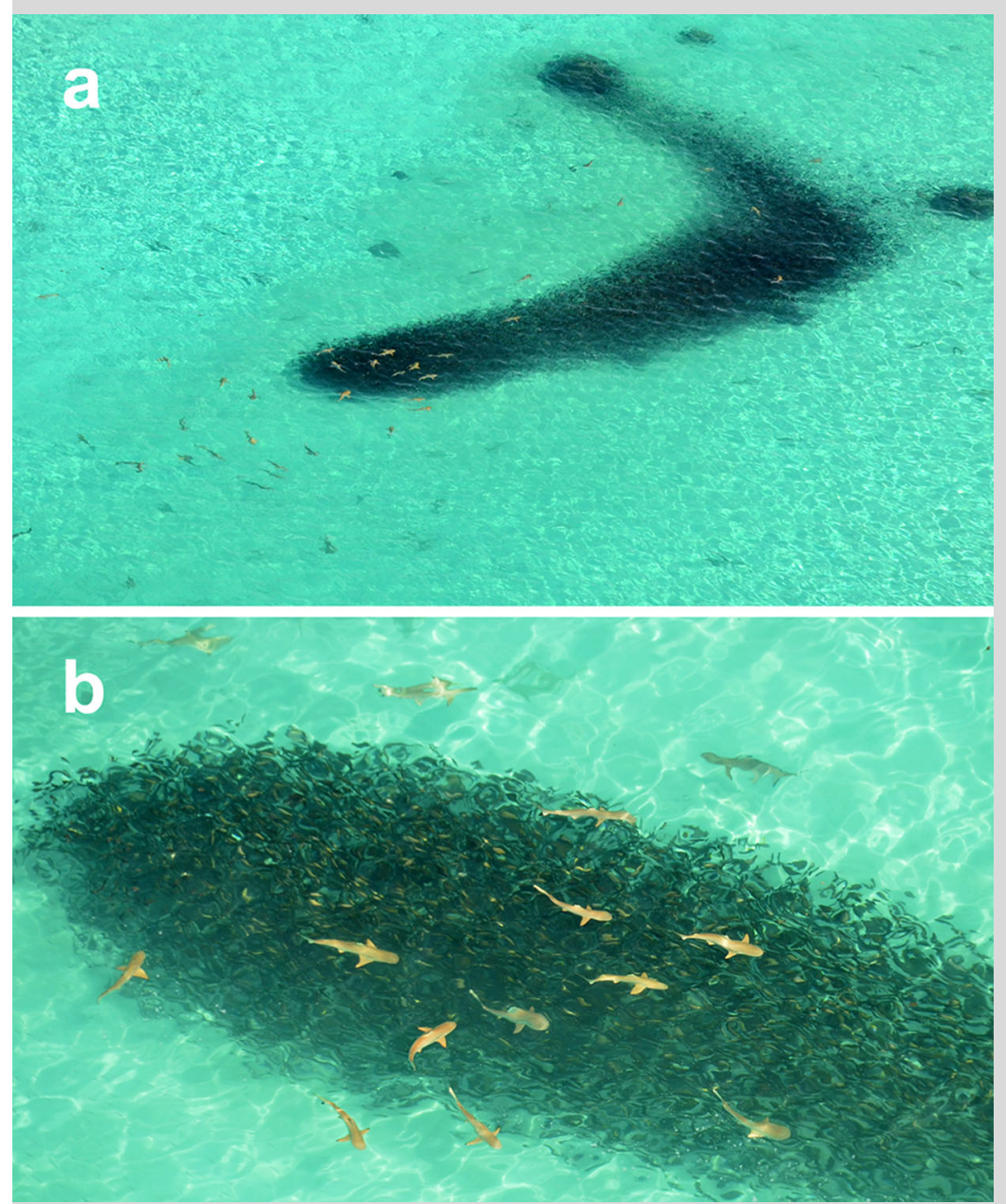

Fig. 1 Carcharhinus melanopterus surrounding a dense aggregation of Ctenochaetus striatus. a Overview of the entire aggregation in the lagoon of Moorea. b Zoomed in view on $C$. melanopterus swimming around the aggregation of $C$. striatus. Note the absence of flight behaviour by $C$. striatus (Photographs Marine National)
During a Navy flight survey around the island of Moorea (French Polynesia) on 18 February 2014, a massive aggregation of striated surgeonfish (Ctenochaetus striatus) surrounded by a minimum of 60 blacktip reef sharks (Carcharhinus melanopterus) was photographed (Fig. 1a). This aggregation of $C$. striatus was observed at $1500 \mathrm{~h}$ in the western lagoon close to the pass of the barrier reef $\left(\mathrm{S} 17^{\circ} 34^{\prime} 28^{\prime \prime} \mathrm{W} 149^{\circ} 52^{\prime} 09^{\prime \prime}\right)$ and occurred during an ebbing tide, 3 days following a full moon (15 February 2014).

This conspicuous fish aggregation away from the safety of their reef habitat most likely attracted individual sharks that are normally widely distributed across the reef (Mourier et al. 2012). Blacktip reef sharks have been shown to form social groups, but the size of the present aggregation is unusual, suggesting a significant and important reason underlying their congregation. Spawning is a likely cause for this fish aggregation, considering the massive size and reduced flight behaviour of the surgeonfish aggregation (i.e. they did not retreat in the presence of so many $C$. melanopterus; Fig. 1b), and that the observation overlapped with the spawning period of $C$. striatus in the Pacific (October to February; Randall 1961). An aggregation of so many large-bodied surgeonfish away from the safety of the reef could potentially result in higher predation rates by $C$. melanopterus, although predation was not directly observed here. However, massive spawning aggregations could be an important opportunistic food resource for reef sharks, especially because spawning events are predictable and repetitive in time.

If predation does occur, this observation further illustrates the potential trade-off between maximizing reproductive success through massive aggregating behaviour and increased vulnerability to predation in spawning reef fishes (Claydon 2004) and further emphasizes the complex trophic interactions in coral reef ecosystems.

Acknowledgments We are grateful to Nicolas Renard and the Marine Nationale for providing us with the photographs. We also thank René Galzin, Jodie Rummer, and colleagues for their useful comments.

\section{References}

Claydon JAB (2004) Spawning aggregations of coral reef fishes: characteristics, hypotheses, threats and management. Oceanogr Mar Biol Annu Rev 42:265-302 Mourier J, Vercelloni J, Planes S (2012) Evidence of social communities in a spatially structured network of a free-ranging shark species. Anim Behav 83:389-401 Randall JE (1961) Observations on the spawning of surgeonfishes (Acanthuridae) in the Society Islands. Copeia 1961:237-238

O. C. Weideli $(\bowtie) \cdot$ J. Mourier $\cdot$ S. Planes

Laboratoire d'Excellence «CORAIL», USR 3278 CNRS-EPHE-UPVD, Centre de Recherche Insulaire et Observatoire de l'Environnement (CRIOBE), BP 1013, Papetoai 98729 Moorea, French Polynesia

e-mail: ornella.weideli@gmail.com 